\title{
RATING AND SELECTION OF OIL CIRCUIT BREAKERS
}

\author{
BY E. M. HEWLETT, I. N. MAHONEY AND G. A. BURNHAM
}

\section{Abstract of Paper}

On account of the variable conditions in systems on which circuit breakers are used, it is impossible to give a simple rule which will cover the selection of circuit breakers for all cases. The authors discuss the interpretations of the A. I. E. E. Standardization Rules covering the rating of oil circuit breakers and consider the variable factors which are involved in the selection of circuit breakers for various systems. A method is suggested whereby short-circuit characteristics of various systems can be used for determining the proper selection of oil circuit breakers for average systems. The method does not apply to very large systems or unusual conditions.

$\mathrm{T}^{\mathrm{H}}$ HERE IS an increasing demand from engineers and operators for a more uniform statement from the various manufacturers with reference to the rating and recommended selection of electrical protective equipment. It appears that simple concise statements might easily be made that would convey definitely the desired information, but there are so many variables which enter into the selection that a simple statement to cover all cases is impossible.

The object of this paper is, (1) to discuss the interpretations of the A. I. E. E. rules covering the rating of oil circuit breakers, (2) to discuss the factors involved in the proper selection of oil circuit breakers, and (3) to suggest average system short-circuit characteristics which can be used for selecting oil circuit breakers for certain systems.

It is hoped that the interpretation given and the data proposed for oil circuit breaker selection will meet with the approval of those persons interested in this problem or give rise to suggestions leading to improvement.

The subject has received careful consideration by the Standards Committees of the American Institute of Electrical Engineers and several papers on this subject ${ }^{1}$ have been presented

1. Rating of Oil Circuit Breakers, by E. M. Hewlett, Transactions, A. I. E. E., 1916; Rupturing capacities of Oil Circuit Breakers, by S. Q. Hayes, Transactions, A. I. E. E., 1916; Rating of Oil Circuit Breakers, by G. A. Burnham, Transactions, A. I. E. E., 1913. 
to the Institute, all of which have resulted in bringing about a clearer understanding of the various expressions and methods used in connection with the rating of this class of equipment.

Circuit breakers are classified according to their rated pressure, rated current, rated frequency and interrupting capacity.

Systems may be classified according to their normal operating pressure, normal current, normal frequency and current transients.

The rated pressure (voltage) of a circuit breaker is the greatest normal pressure in r.m.s. volts between any two wires of any circuit to which the breaker should be connected.

The Standardization Rules of the American Institute of Electrical Engineers require that oil circuit breakers for voltages above 600 volts withstand a dielectric test ${ }^{2}$ of 2.25 times rated pressure plus 2000 volts for 60 seconds. Although not stated in the rules we infer that it contemplates a test with the apparatus under dry conditions.

The normal operating pressure of a system is the greatest pressure in r.m.s. volts ordinarily maintained between any two conductors.

The rated current of a circuit breaker as defined by the A. I. E. E. ${ }^{3}$ is "the normal r.m.s. current which it is designed to carry." This rating is covered by the following rule."

"Temperature Tests-Rated current at rated frequency shall be applied continuously until the temperature becomes constant. The maximum temperatures of the various parts shall not exceed the following when the ambient temperature of reference is 40 deg. cent.:

Contacts in air...............

Oil and contacts therein...........70 deg. cent.

Coils (See sections $376-379$ incl.) ${ }^{5}$

Other parts (see section 392$)^{6}$

Contacts in air may be subjected to an ultimate temperature at $70 \mathrm{deg}$. cent. for periods of short duration.

2. Rule 755. June 1917, supplement to A.I.E.E., Standardization Rules.

3. Rule 752, June 1917, Supplement to A.I.E.E. Standardization Rules.

4. Rule 754, June 1917, Supplement to A.I.E.E. Standardization Rules.

5. The rules referred to herein, limit the maximum permissible temperature rise of coils to temperatures determined by the insulating materials used.

6. The rule referred to above reads in part as follows: "All parts of electrical machinery other than those whose temperature affects the temperature of the insulating material may be operated at such temperatures as shall not be injurious in any other respect." 
"The Institute recognizes the inherent decrease in capacity of switch and circuit-breaker contacts in air, due to oxidization of the contact surfaces. The rating of air switches and circuit breakers is, therefore, based on sufficient maintenance to keep the temperature within the specified limits."

The normal current in a circuit of an electrical system is the rated current in r.m.s. amperes for which that circuit is designed.

The actual current may vary through wide limits from day to day and at different seasons of the year. The upper limit for continuous operation or the rated current is, however, fixed by the capacity of the conductors as determined by the maximum allowable temperature at which the conductors and their insulation may be operated.

The interrupting (rupturing) capacity of a circuit breaker as specified by the Standardization Rules ${ }^{8}$ of the American Institute of Electrical Engineers is:

"—- the highest r.m.s. current at normal voltage which the device can interrupt under prescribed conditions at stated intervals a specified number of times."

It is recognized that factors anticipated in the above rule as the "prescribed conditions" may affect the interrupting capacity of the breaker. Such factors are discussed under the section: "Present Interrupting Capacity Rating."

The "stated intervals" and "specified number of times" at a given current and pressure determine the duty imposed upon the breaker. The breaker interrupting capacities in r.m.s. amperes published by various manufacturers are based on an assumed duty, i.e., that the breaker will interrupt its rated r.m.s. current two times at a two minute interval and then be in condition to be closed and carry its rated current until it is practicable to inspect it and make necessary adjustments.

The duty, including a statement of the "prescribed conditions" therefore, places a limit on the interrupting capacity of a breaker and any change in duty or prescribed conditions will necessarily affect, the rated interrupting capacity.

\section{Previous Interrupting Capacity Ratings}

It has been the practise in the past to state the interrupting capacity of circuit breakers in terms of the total alternator capacity in $\mathrm{kv}-\mathrm{a}$. at a specified reactance. In rating a circuit

8. Rule 753, June 1917, Supplement to A. I. E. E. Standardization Rules. 
breaker in these terms, consideration was given to the shortcircuit characteristics of the machines together with the characteristics of the circuit breakers and relays.

The "arc kv-a." ratings as previously listed were derived by multiplying the interrupting capacities in amperes by an assumed value of pressure. This assumed value was considered as the probable pressure that would be re-established on the bus immediately after the short circuit was cleared or that occurring during the clearing. The "arc kv-a." rating, based on the assumption that the re-established bus pressure will be normal, can be obtained for three-phase circuits by multiplying the interrupting capacity of the breaker in amperes by the normal pressure in volts of the circuit to which it is connected, and by the factor 1.73 divided by 1000 .

It is to be noted that the interrupting capacity rating specified by the A. I. E. E. in r.m.s. current anticipates normal pressure to be re-established. Systems having characteristics such that the re-established pressure during short circuit will be higher than normal, will require a larger breaker.

As power stations have increased in capacity, and transmission and distribution net works extended, considerable reactance is introduced between the alternators and the point of short circuit which limits the current appreciably, and the total alternator capacity is no longer a measure of the severity of the short circuit. Service considerations are becoming more severe and larger and more expensive circuit breakers are required. A method of rating circuit breakers that will allow of more accurate selection for a wide range of conditions is desirable.

\section{Present Interrupting Capacity Rating}

The rating of a circuit breaker in r.m.s. current interrupted at normal operating pressure simplifies the selection of a proper breaker for a given service condition. Such a rating makes comparative tests possible if a sufficient amount of power is available.

In the A. I. E. E. rule establishing this rating it is qualified by the words "prescribed conditions". It is generally recog. nized, indicated by test and by the operation of circuit breakers in service, that the power factor or the stored electrostatic and magnetic energy of the system are among the conditions affecting the interrupting capacity at a given r.m.s. current. During the current-opening periods an arc is established, and 
the current and voltage relations during this period are much more complicated than the simple phase-angle relation covered by the statement of power factor. Furthermore, the arc may be re-established under transient voltage conditions, still further complicating the phenomena. The theoretical and empirical data available on the effect of these conditions on the work done by the breaker are not at present adequate for the authors to prescribe any particular power factor for test, or to suggest any method for general use, to take into account the power factor and energy storage characteristics for all systems. These factors are of special importance when a breaker of relatively small interrupting capacity is connected to a large system in such a way that the breaker may afford the only outlet for the stored energy of the system. Such influences, while extremely difficult to take into account, will not differ widely in average systems. They are taken into account in a general way in the factor of safety employed in the rating of a breaker and their effects need not be considered in ordinary individual problems.

Selection of breakers for unusual conditions, large systems, or those involving large investment, should be checked with the manufacturers.

For average systems, a determination of the r.m.s. current that will flow at the instant the contacts part, irrespective of power factor or circuit conditions, will enable one to select the proper circuit breaker.

\section{Determination of Short-Circuit Current}

In order to determine the r.m.s. current that the circuit breaker will be required to open, an analysis of short-circuit phenomena on an alternating-current net work is necessary, and it may be desirable to call attention to some of the conditions under which circuit breakers may be called upon to function.

Short-circuiting a system at any point permits an abnormal current to flow immediately in that system. The amount and persistency of this current rush depend upon the characteristics of the synchronous apparatus connected to the system at the time, and upon the impedance in circuit between the synchronous apparatus and the point of short circuit. The value of r.m.s. current which the circuit breaker will be called upon to interrupt, will depend upon the length of time that elapses between the start of short circuit and the parting of the contacts as will be seen from the following analysis of short circuits. 
The greatest transient disturbance of the system which can occur at the point of application of the circuit breaker when the system is short-circuited, governs the selection of a suitable breaker. A diagram showing the current flowing in one phase of the external circuit when a system is short-circuited under ordinary operating conditions, is shown in Fig. 1. In this diagram $O$ is the origin of the co-ordinates and is taken at the instant at which the short circuit occurs. $O X$ is the axis of abscissas and the abscissas represent time. $O Y$ is the axis of ordinates and the ordinates represent current. $C D$ is a curve passing through the maxima of the wave of the total current and $E F$ is a curve passing through the minima. $A B$ is a curve

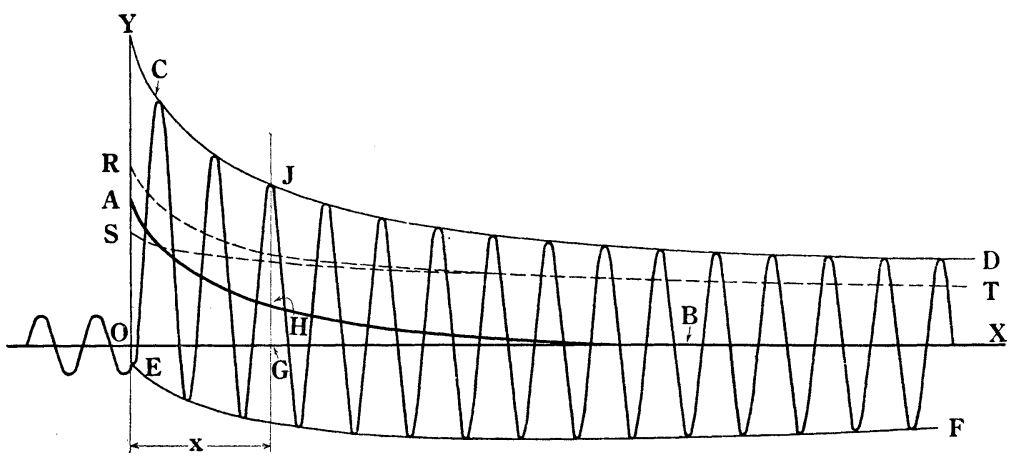

FIG. 1

Generator characteristics--illustration of behavior of generator current when short circuited from full load at 0.8 power factor

which cuts the vertical everywhere midway between $C D$ and EF

The wave of total current whose crests lie along curve $C D$ and $E F$ and whose ordinates are measured from the axis $O X$ may be regarded as having two components, namely,

1. A direct component

2. An alternating component.

The direct component is represented at any time by the ordinate to the curve $A B$ or at the time $x$ by the ordinate $G H$.

The alternating component is a wave whose crest value at any time is the difference between the ordinates to the curves $C D$ and $A B$. This difference, at the time $x$, has the value $H J$. The r.m.s. values of this alternating component are shown on curve $S T$. At any instant this component is considered to have the same r.m.s. value as an alternating wave of constant ampli. 
tude whose crest value is represented by one half the distance between curves $C D$ and $E F$ at that instant.

The r.m.s. value of the total current wave under short circuit at any instant is the square root of the sum of the squares of the value of the direct component and the effective value of the alternating component at that instant. It is represented by the curve $R . T$. This r.m.s. value of the total current at the time of parting of the circuit-breaker contacts is used in making circuit-breaker applications.

The r.m.s. current at any point of a system under shortcircuit conditions is affected by the following factors.

1. The total $\mathrm{kv}-\mathrm{a}$. reactance and transient characteristics of the synchronous machines connected to the system.

2. Number, reactance, resistance, capacitance and arrangement of all circuits over which power can be supplied to the point of short circuit.

3. The kv-a., arrangement, resistance, reactance and capacitance of all reactors and transformers through which power can be supplied to the point of short circuit.

4. Contact resistance at the short circuit.

5. The nature of the short circuit, whether single-phase or multiphase.

6. The $\mathrm{kv}-\mathrm{a}$. and power factor of the load being carried at the time of the short circuit.

7. The point of the pressure wave at which the short circuit was established.

8. The use of automatic voltage regulators.

The short-circuit transient for systems may be determined by test, by calculation or, less closely, by assumption. Obviously, the determination by test for all circuits of a large system is expensive and involves considerable time and interruption to service. This will be practicable in but few cases. The determination by calculation is also a matter of considerable labor but is feasible if only the important factors listed above are considered. Practical approximate selection, sufficiently accurate for many cases can be made by using only reactance and an accepted group of time-current decrement curves.

Suggested decrement curves are shown on Figs. 2 and 3 and their ordinates on Table I.

These curves are based on the following assumptions: Transient characteristics for alternators of normal design determined from oscillograph tests: That the effect of capacitance and resistance is neglected: That the contact resistance at short 
circuit is zero: That the alternator is carrying full load 80 per cent power factor: That the short circuit was established at the point of the pressure wave corresponding to maximum possible

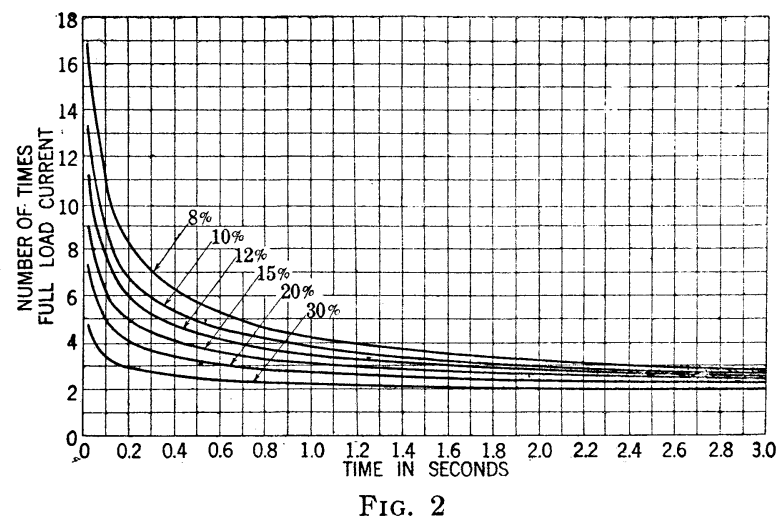

System short-circuit characteristics-8, 10, 12, 15, 20 and 30 per cent total reactance based on total $\mathrm{kv}$-a. rating of synchronous machines

Time-current curves-r. m. s. current in terms of total full-load current of machinesinitial full load at 0.8 power factor assumed

instantaneous current: That no automatic voltage regulators are used.

These curves differ from those that have been usually considered in the past for two reasons: first, r.m.s. values are used

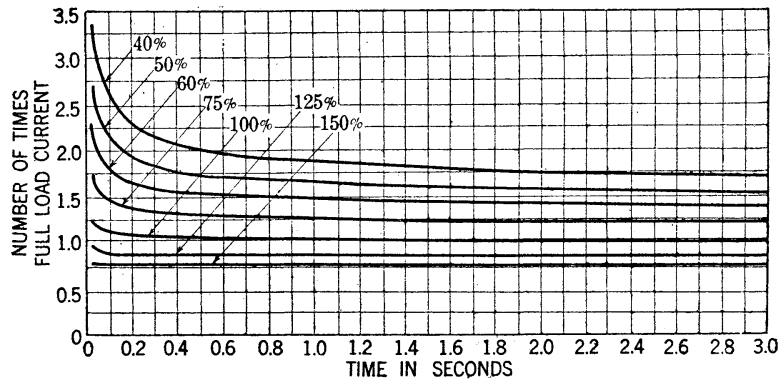

Fig. 3

System short-circuit characteristics-40, 50,60,75, 100, 125 and 150 per cent total reactance based on total $\mathrm{kv}-\mathrm{a}$. rating of synchronous machines

Time-current curves-r. m. s. current in terms of total full-load current of machinesInitial full load at 0.8 power factor assumed

instead of peak values; and second, the effect of the increased flux existing under the load condition assumed has been taken into account.

The effect of using r.m.s. values instead of peak values is to 

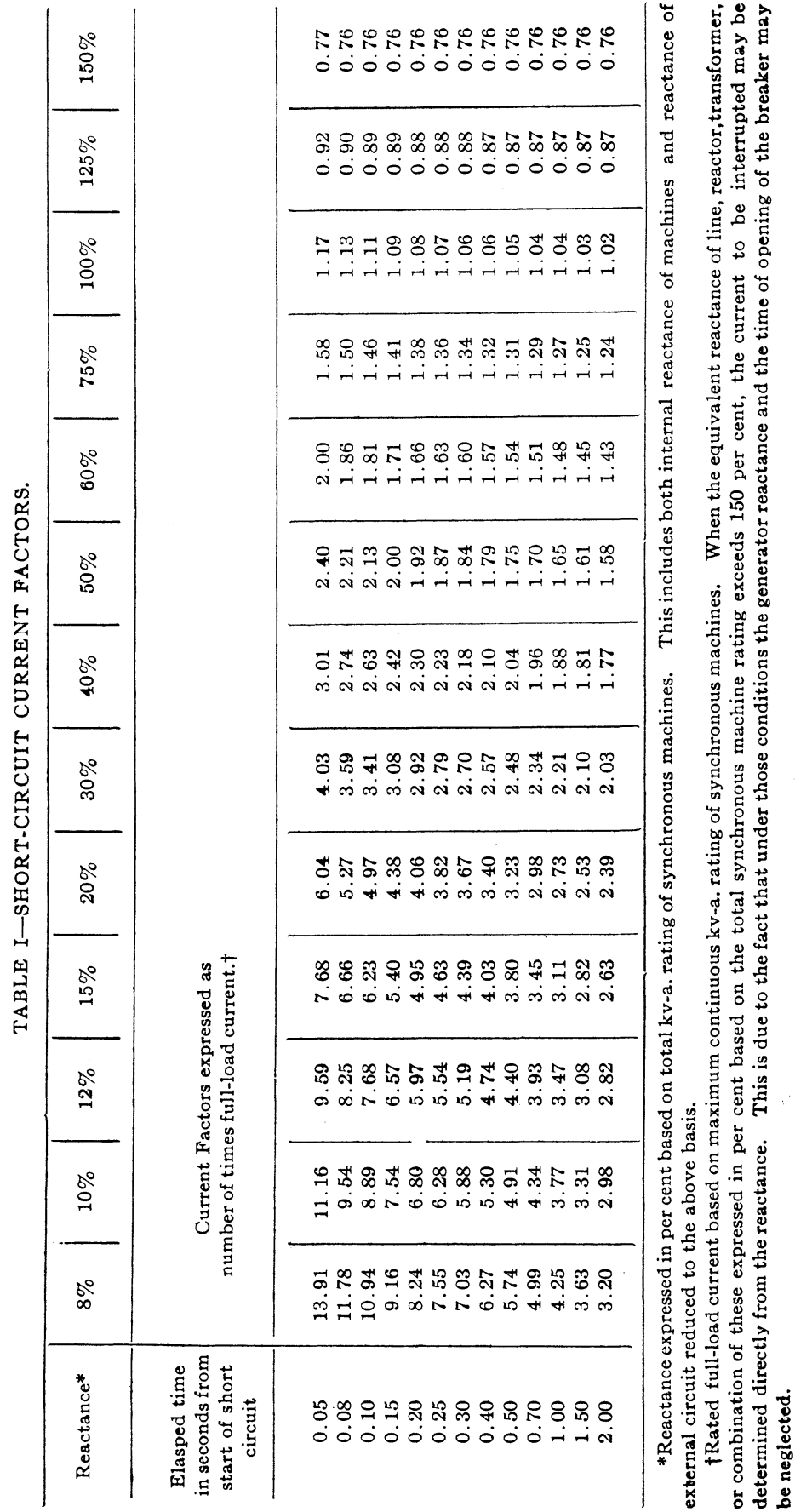
appreciably reduce the ratio between short-circuit and rated amperes. For example, assuming 10 per cent reactance and a short-circuit current containing the maximum possible direct component, the ratio of the peak value of the first alternation of the short-circuit current to the peak value of rated current is roughly twenty. Under the same conditions the ratio of the r.m.s. value of the first alternation of the short-circuit current to the r.m.s. value of the sinusoidal rated current is roughly seventeen.

The effect of using the flux at rated voltage and the assumed load instead of at rated voltage and no-load is to increase the short-circuit current by a somewhat less percentage than the alternator reactance percentage. This effect in alternators of low reactance relatively is unimportant but assumes increasing importance as the alternator reactance increases.

The characteristic shapes of the time-current decrement curves have been arrived at by analysis of alternator tests including oscillograph studies of short circuits occurring when the alternators were excited to full voltage and were carrying various loads at various power factors.

In the curves for total reactances up to and including 20 per cent, the reactance is assumed to be wholly within the alternator and for higher values of reactance the alternators were taken at 20 per cent and due allowance made by calculation for the effect of the external reactance. In the latter case, if alternators of other reactance had been assumed the results would have been somewhat different but the error is not large enough to be of practical importance.

The final values of the current i.e., the sustained short-circuit current, have been assumed in accordance with experience and tests and are based on the behavior of machines of normal design.

The study of representative oscillograms of short-circuit tests showed that in most cases the direct component disappeared within 0.5 second and that the transient portion of the alternating component disappeared within 3.0 seconds. These time values have therefore been used in constructing the characteristic curves.

Several alternators with the same reactance and synchronous impedance will not necessarily have the same rate of r.m.s. current decay. This has been considered in constructing the characteristic curves and they may safely be taken as representing the greatest r.m.s. currents that will be given by modern alternators of normal design. 
These curves are applicable for selecting circuit breakers for systems as follows

1. Single machines without external reactance.

2. Single machines in combination with external reactance.

3. Multiple machines with no external reactance.

4. Multiple machines in combination with external reactance.

\section{EXAMPLES}

In order to illustrate the use of these curves in making oil circuit-breaker selections, the following examples are given:

Example 1. (Arrangement of apparatus shown in Fig. 4.) Alternator rating $5000 \mathrm{kv}$-a., 2300 volts three-phase, $1250 \mathrm{am}$ peres. Breaker contacts part in 0.25 second after start of short circuit. From table, under 12 per cent reactance, we find that at 0.25 second the current will be 5.54 times normal, therefore

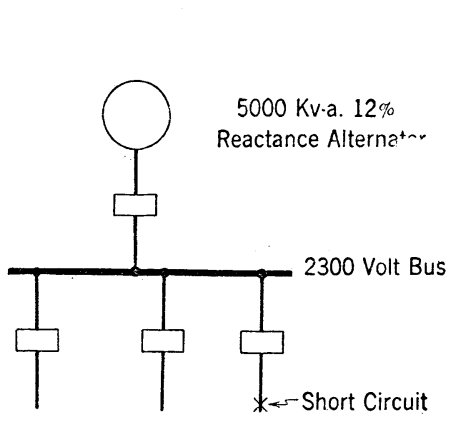

FIG. 4

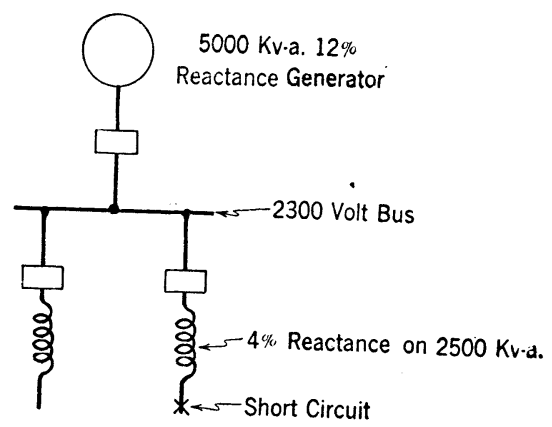

FIG. 5

the short-circuit current equals $5.54 \times 1250$ amperes $=6950$ amperes.

Example 2. (Arrangement of apparatus shown in Fig. 5.) Alternator rating $5000 \mathrm{kv}$-a., 2300 volts, three-phase, $1250 \mathrm{am}$ peres. Feeder rating $2500 \mathrm{kv}-\mathrm{a}$. Feeder reactance 4 per cent based on $2500 \mathrm{kV}$-a. Breaker contacts part in 0.25 second after start of short circuit.

Alternator reactance based on $5000 \mathrm{kv}-\mathrm{a} .=12$ per cent Feeder

$$
\begin{aligned}
& \text { " " " " } " 8 \text { per cent } \\
& \text { " " " } "=\overline{20} \text { per cent }
\end{aligned}
$$

Total

From the table under 20 per cent reactance, we find that at 0.25 second the current will be 3.82 times normal, therefore the short-circuit current equals $3.82 \times 1250$ amperes $=4780$ amperes. 
Example 3. (Arrangement of apparatus shown in Fig. 6.) Alternator $A$ rated $2000 \mathrm{kv}$-a., 2300 volt, three-phase reactance $=8$ per cent

Alternator $B$ rated $5000 \mathrm{kv}-\mathrm{a} ., 2300$ volt, three-phase reactance $=12$ per cent Alternator $C$ rated $8000 \mathrm{kv}-\mathrm{a} ., 2300$ volt, three-phase reactance $=16$ per cent

Total alternator kv-a., 15,000

Normal current based on $15,000 \mathrm{kv}-\mathrm{a}$., 2300 volts $=3760$ amperes. Breaker contacts part in 0.4 second after start of short circuit. Alternator $A$ reactance based on $15,000 \mathrm{kv}-\mathrm{a} .=60$ per cent

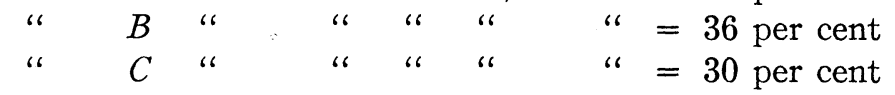

Total reactance at bus $=1 / 60+1 / 36+1 / 30=12.9$ per cent.

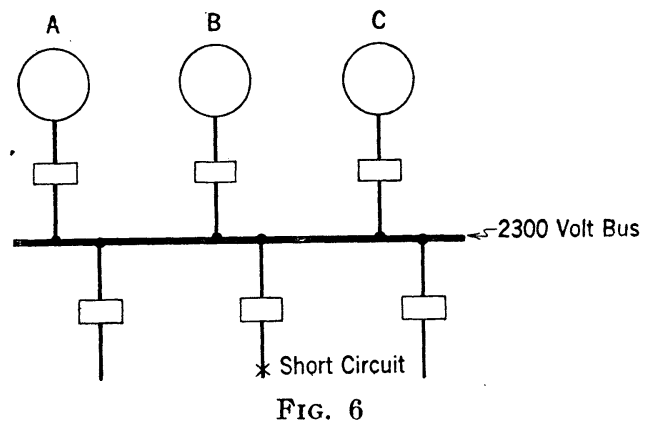

From the table, interpolating between 12 per cent and 15 per cent reactance, we find that at 0.4 second the current will be 4.53 times normal; therefore, the short-circuit current equals $4.53 \times 3760$ amperes $=17,030$ amperes.

Example 4. (Arrangement of apparatus shown in Fig. 7.) Same as example 3, excepting that power is distributed over $2500 \mathrm{kv}$-a. feeders in which are installed current limiting reactors having a reactance of 3 per cent based on $2500 \mathrm{kv}-\mathrm{a}$.

Breaker contacts part in 0.4 second after start of short circuit. Total alternator reactance based on $15,000 \mathrm{kv}$-a. $=12.9$ per cent Feeder " " " " " $=18$ per cent Total " " " " $\quad=30.9$ per cent

From the table using 30 per cent reactance, we find that at 0.4 second the current will be 2.57 times normal: therefore, the 
short-circuit current equals $2.57 \times 3760$ amperes $=9650 \mathrm{am}$ peres.

Example 5. (Arrangement of apparatus shown in Fig. 8.) Breaker contacts part in 0.1 second after start of short circuit.

Alternators same as for example 3.

Transformer banks each $7500 \mathrm{kv}-\mathrm{a}$.; reactance $=6 \frac{1}{4}$ per cent based on $7500 \mathrm{kv}-\mathrm{a}$.

Lines: 20 miles of $1 / 0$ copper; reactance $=5.5$ per cent based on $7500 \mathrm{kv}-\mathrm{a}$. at 60 cycles and 44,000 volts with 4 -ft. conductor spacing.

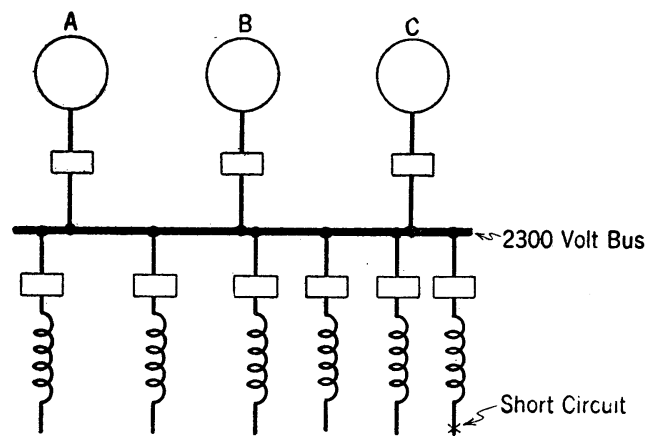

FIG. 7

Total alternator reactance based on $15,000 \mathrm{kv}-\mathrm{a} .=12.9$ per cent.

Parallel reactance of step up transformers

$$
\begin{aligned}
& \text { " " lines } \\
& \text { based on } 15,000 \mathrm{kv}-\mathrm{a} .=6.25 \text { per cent } \\
& \text { based or } 15,000 \mathrm{kv}-\mathrm{a} .=5.5 \text { per cent } \\
& \text { " step-down transformers } \\
& \text { based on } 15,000 \mathrm{kv} \text {-a. }=6.25 \text { per cent } \\
& \text { Total reactance............. }=30.9 \text { per cent }
\end{aligned}
$$

From the table, using 30 per cent reactance, we find that at 0.1 second the current will be 3.41 times normal. The normal current based on $15,000 \mathrm{kv}$-a., 11,000 volts, three-phase $=788$ amperes; therefore, the short-circuit current equals $3.41 \times 788$ amperes $=2690$ amperes.

Example 6. (Arrangement of apparatus shown in Fig. 9.) Breaker contacts part in 0.4 second after start of short circuit. Conditions same as for example 5 except that a $475-\mathrm{kv}-\mathrm{a}$., 2300-volt feeder has been added to the low-voltage distribution. 
Transformer reactance, 3 per cent based on $475 \mathrm{kv}$-a.

Total reactance up to 11,000 -volt bus

based on $15,000 \mathrm{kv}-\mathrm{a} .=30.9$ per cent

Feeder transformer reactance

based on $15,000 \mathrm{kv}-\mathrm{a} .=94.5$ per cent

Total reactance based on $15,000 \mathrm{kv}$-a.

$=125.4$ per cent

From the table, using 125 per cent reactance, we find that at 0.4 second the current will be 0.87 times normal. The normal current based on $15,000 \mathrm{kv}$-a., three-phase 2300 volts $=3760$

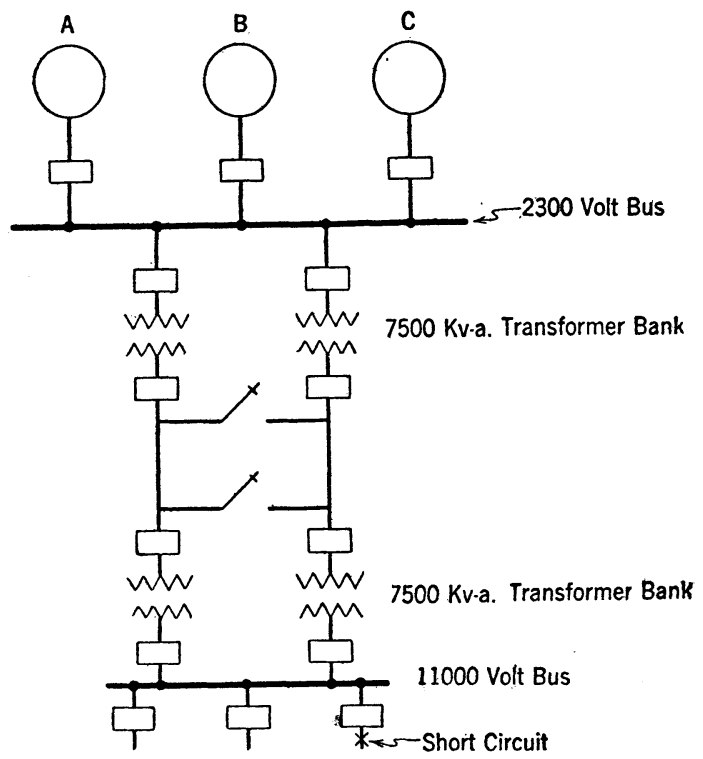

FIG. 8

amperes, therefore the short-circuit current equals $0.87 \times 3760$ amperes $=3270$ amperes.

With reactance of 125 per cent or higher values, the alternator portion of the total reactance becomes of small importance. In example 6 for instance, we have a total reactance of 125.4 per cent. The alternators in this example have a reactance of 12.9 per cent. If the reactance of the external circuit only is considered we have a total reactance of 125.4 per cent -12.9 per cent $=112.5$ per cent.

The short-circuit current on this basis would be

$$
\frac{100}{112.5} \times \text { normal, or } 0.890 \times 3760=3340 \text { amperes. }
$$


Comparing this value with the 3270 amperes obtained by considering the alternator reactance we have an error of approximately 2 per cent.

If the total reactance is greater than about 125 per cent or 150 per cent, the error will be even less than 2 per cent. For values of external reactance in excess of the table values the alternator reactance may be omitted.

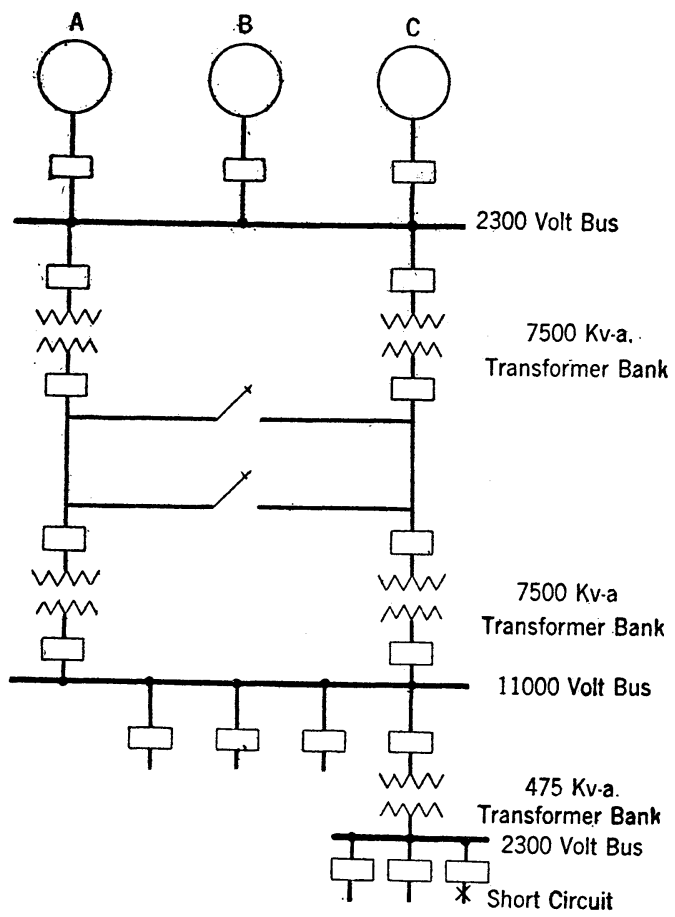

FIG. 9

\section{Precautions}

The data given for the selection of oil circuit breakers is applicable only to average systems. Therefore, a short discussion of other factors requiring separate or more detailed attention seems worthy.

Automatic voltage regulators may introduce system transients differing from those which occur on systems not so equipped.

When the alternators are equipped with automatic voltage regulators such regulators will increase the excitation after a short circuit in the endeavor to hold normal voltage on the bus 
bars. The maximum voltage which can be obtained from the exciters will ordinarily be not more than 50 per cent greater than that required at full load, 80 per cent power factor on the alternators. Under short circuit, the alternator terminal voltage is reduced, hence the resultant flux density in the alternator iron is also reduced. A given increase in excitation, therefore, produces a proportionate increase in current flowing in the short circuit. Hence, as we have assumed the excitation to increase 50 per cent, the sustained short-circuit current will be approximately 50 per cent greater than the sustained current due to full-load 80 per cent power factor excitation.

An appreciable time, however, is required for the excitation to increase to its maximum value. During the first half second the amount of short-circuit current is not affected by the presence of the voltage regulator, but from this time on the current curve is higher, reaching the value at the end of two to three seconds of 50 per cent greater than the current without the regulator.

An exception to the above appears when the external reactance is so high and the short-circuit current so limited that the regulator is able to maintain normal voltage at the generator terminals. In such cases the sustained current may not be increased as much as 50 per cent, but will be limited to the current which will pass through the external reactance with normal voltage impressed upon it.

The interval between the occurrence of the short circuit and the parting of the circuit breaker contacts has, as study of the selection curves will show, an appreciable bearing on the oil circuit breaker that will be selected. The time values usually given for the operation of breakers assume that the breakers have been properly maintained and that their operation will not be impaired by factors resulting from neglect of maintenance or adjustment.

It is believed that the manufacturers of oil circuit breakers should publish information similar to that outlined in this paper to serve not only as a guide in the application of electrical protective devices but also to assist in bringing about a more uniform selection and a better understanding of the various expressions and methods used in connection with the rating of this class of equipment. 
Discussion on "Rating and Selection of Oil Circuit Breakers (Hewlett, Mahoney and Burnham), New York, February 15, 1918.

E. M. Hewlett: What we have been struggling with is to make a "Bench Mark" from which we can all start and work out a common language. In the past the folks who were working on generators, on reactances, on transformers and on the lines outside. kad each their own problems and their own equations, which caused much confusion, and this confusion was further added to because they did not all use words in the same way'.

Then, as to the quantity and character of amperes usedwhen we were called upon to interrupt larger capacities as the generator grew larger, we asked the question, what is the current we are to interrupt? We were told by the calculators that it was about three times full-load current,- but we knew we were experiencing currents much larger, that is to say, we felt this even before we had the oscillograph and before we could tell anything from the swing of the ammeter, etc. Finally we obtained an oscillograph and discovered that we had swings that ran up many times, - - ten times or so. But then in figuring these amperes, sometimes figured from the zero line, sometimes symmetrically and sometimes unsymmetrically, we found it very difficult to get an agreement, thus the papers presented in Boston a year or so ago started the work of bringing the terms together.

In our work on this paper with the different companies, we have looked over the various generator curves and determined their characteristics, how they average, etc., and have found that it was possible to do a thing that we did not think would be possible, that is, to make a general characteristic curve that was close enough to be within a negligible error. We realized that there may be machines above and below that curve, but consider those as special conditions, and they should be recognized and considered as such.

Now, as to the testing equipments, and the different tests to determine the rupturing capacity, etc., we have been getting larger tests and tests on different plants.

Of course, it is very difficult to get the use of the line and the plant to test $100,000 \mathrm{kw}$., etc., so that we have only been able to establish a series of tests on smaller capacities, and have had to depend on the tests in operation, incidental short circuits, etc., and the readings taken at that time and observations made that would indicate the limits of switches, so as to give a rating.

We hope later to be able to make tests and to check up and settle definitely all of these different ratings. The work, however, will be carried on as rapidly as possible, and the line extended as capacities are available and as different tests are made available.

The information that we get in reference to the effectiveness of the circuit breakers, etc., is very conflicting. We find that one man will say, "Why, yes, it works fine. It opened the 
circuit." Then you ask him, "Well, what happened to the circuit-breaker." He will reply, "well, we got the circuit breaker fixed up before we could get the trouble fixed up, but that was all right." Another man will say, "We had a great deal of trouble." Probably he had blown out a half pint of oil and that had bothered him, so that the different viewpoints of the user are not standardized, either.

The kilowatt rating that we formerly used was a great convenience up to a certain point, and we will have now a kilowatt rating to be used on transformers; that is, a transformer limit, a rating that will show the size of transformers that can be used with a given breaker, to limit the capacity and make the breaker of easier application.

If we can get any constructive criticism and help as to what can be done in the way of getting tests, and in standardizing so that we can use the information we have, that is, the fundamental characteristics and r. m. s. current values, we will feel as though quite a step will have been made, and other papers will be brought out from time to time that will finally put the industry in this respect more in the shape of a science than of an art.

J. N. Mahoney: In reference to the data suggested, in this paper, as the basis of comparison of "Interrupting capacity" rating between the different manufacturers. Some may question the data, as not being derived from service practise. We state the device obeys Institute Rules regarding "duty" rating by interrupting specified power two times at a two-minute interval. In practise there are all degrees of requirement, ten operations some want, and others are satisfied with a single successful interruption. The natural trend of practise is that requirements are not constant-they change from operation to operation, whereas the condition specified by the Institute rule is necessarily constant, such as a given maximum of amperes. We assume that the usual short-circuit current may be only a fraction of the current interrupting guarantee specified which contemplated maximum conditions. In practise we have found that interrupting the actual maximum two times at a two-minute interval permits of more operations under average conditions. The current is less, maybe one-half, and you get approximately ten operations with little depreciation of the breaker details, as the "short" is out on the line and not at the breaker." I mention this so that it will not be inferred that two operations are the only duties the breaker is good for. It is good for all the operations you want as long as the oil and contacts are in reasonable condition.

Henry R. Summerhayes: In the paper there is mentioned the present interrupting capacity rating, and in connection with that rating the words "prescribed conditions" are used. I want to make some comments on "prescribed conditions." They were presumably put in the Institute Rules as to interrupting 
capacity in order to allow conditions to be described, when we knew enough about the theory of the circuit breaker operations to describe conditions under which tests could be made. The theory is not in a very satisfactory state. Of course, it is generally recognized that the work imposed on the circuit breaker is the kv-a. used up or dissipated in the circuit breaker during the time it is opening, and another element that may appear to have a bearing on that and at first sight a very simple relation is the power factor of the current flowing in the short circuit.

If the current wave and the voltage wave are in phase, 100 per cent power factor, and if according to observations, as circuit breakers ordinarily do, the circuit is opened at the zero of the current wave, the voltage wave is at that time zero, and there is little tendency to establish the arc. If, on the other hand, you have 90 deg. lag., so that the current ceases to flow at the moment when the voltage is at a maximum you apparently have the worst condition, the tendency to re-establish the arc, due to voltage being high.

In the case of most of the short circuits the reactance in the circuit predominates, and the power factor is low, ordinarily varying from zero, or nearly zero to about 20 per cent. With that variation perhaps the voltage wave is fairly flat, and at nearly the maximum voltage, so that ordinary variations of the power factor, theoretically, should not make much difference in the working of the circuit breaker, but if the power factor is very high, then the work is apparently less. That is based on the assumption that the current and voltage during the period of circuit breaker opening follow a sine wave. From this point of view it would appear that the work imposed on a circuit breaker would not vary much for power factors from zero to about 20 per cent, because if the current and voltage during the period of circuit breaker opening follow sine waves, and the current ceases to flow at zero of the current wave, the voltage tending to re-establish the arc will be nearly at the maximum point of its wave, for a variation of power factor from zero to about 20 per cent.

However, the arc in the breaker may set up oscillations in the system superimposing high frequencies on the simple sine waves with reestablished voltages in the circuit breaker higher than the circuit voltage, and with varying phase relation between the voltage and current, so the simple relations no longer exist, and it is difficult to determine by test or in any other way the actual power factor existing at that time.

It is generally assumed that the presence of high reactance and low power factor in the circuit increases the electromagnetic storage of energy which may have to be dissipated in the circuit breaker by these oscillations, and therefore may present a severer condition for the breaker to handle than when the current in the circuit is limited chiefly by the resistance which 
absorbs the energy of oscillation. According to that view, the observed fact that the circuit breaker has an easier time when the power factor is high may depend on the absorption of the energy oscillations by resistance; that is, the resistance in the circuit predominates rather than being dependent directly on the power factor. The power factor during short circuit may also be affected by the resistance in the arc.

Due to these considerations it would appear, as stated in the paper, that the data available are not sufficient to state how much the interrupting capacity of the breaker is affected by the relative resistance, reactance and capacitance of the circuit. Apparently we have not enough data to prescribe at what power factor the tests should be made.

As the authors point out, the average circuit has parallel feeders and the breaker will seldom be required to dissipate all of the stored energy of the system; in other words, when you have parallel feeders with more or less non-inductive load, it is thought that these act as a resistance, and take up part of the energy. If you set up test conditions, with all of the generators running, and a single feeder, and have the circuit breaker on that feeder, it is a more severe condition than if the breaker opens the same amperes, but with three feeders running in multiple.

It is believed that average systems are generally similar as to the conditions of stored energy, electrostatic and electromagnetic, so that the test conditions are generally more severe than the service conditions, and the curves given in the paper will probably be safe for nearly all conditions.

W. W. Willard: The statement is made that the accurate calculation of the currents that will result from short circuit is usually not practicable, because of the dearth of data for the purpose, and also because of the alternator power; and certain suggested diagrammatic curves, shown in Figs. 2 and 3 , are offered as a means of determining the excess currents that will result in varying cases from short circuits.

It is worth while to note, however, that under "Precautions," the data given for the selection of oil circuit breakers are applicable only to average systems. We are also reminded that the selection of circuit breakers for unusual conditions, large systems, etc., should be checked with the manufacturers. One of the sets of conditions under which this would seem to be desirable is suggested. This suggestion reminds us that the curve indicated for this purpose should take into account the nature of the short circuit, that is, whether it is single-phase or multiphase. There are several ways in which a short circuit can occur on a system, especially on a polyphase system, and one of these is a case in which all of the legs of the circuit are involved.

One of them is a common case, in which only two legs are involved, and another is the case where a single leg of a circuit is involved in a ground on a system which is $Y$ or star-connected, 
with ground neutral; or in the case of 3-phase, 4-wire circuits, in which there is a short circuit from one of the phases to the neutral.

The curves proposed in this paper have been drawn in such a way as to include a factor of safety sufficient to provide for the case of a short circuit in which all of the legs of the circuit are involved, ard also for the majority of cases where singlephase short circuits occur on polyphase systems, notwithstanding the fact that a single-phase short circuit occurring at the terminals of a polyphase generator may and usually will result in higher values for the sustaining current, that is the current which will exist for a lapse of say, two or three seconds, than would be the case if all the legs of the circuit had been involved in the short.

It is believed also that the curves are drawn high enough to provide for the common case of a ground on one leg of a Yconnected system, with grounded neutral, or of a short circuit from one leg to reutral, unless the neutral is brought out from all of the generators, or all of the generators grounded with current limiting resistance or reactance. If only one of the generators is grounded, and there are several generators, so that the reactance of the grounded generator, figured on the accurate capacity of the generators, is within the limits of the table, such a generator might operate as a ground to a limited reactance. If, however, no such condition exists, and it is desirable to apply a circuit breaker between a generator having a grounded neutral and a generator bus, that is to say, on the generator side of the first transformer bank, the current resulting from a short circuit of that kind will probably be high enough to make it necessary to exercise extra precaution, and to consider that one of the exceptional cases, that will require us to learn the magnitude of such currents from other sources than the curves given in this paper, as the curves given are hardly suitable for that purpose.

Bassett Jones: I speak from the point of view of the man who has to advise another man how to invest his money in circuit breakers. The paper presents a very definite, easily understood method of determining the duty that may be imposed on an oil circuit breaker. Except in a very general way, it does not determine a method of selecting any particular variety of breaker. This latter problem has always been shrouded in deep mystery, particularly in view of the fact that so many varieties of breakers have been devised to meet such a multitude of special conditions, that the manufacturers' catalogues and published ratings are not always of use. By this I mean that even when the duty required has been determined by the method outlined in the paper, it does not necessarily follow that the proper or rather the most economical type of breaker can be selected directly from a catalogue or hand book.

A case develops in which with, say, a rated full-load capacity of $12,500 \mathrm{kv}-\mathrm{a}$., 10 per cent reactance in each generator con- 
nected to the bus, and with what may seem a reasonable per cent of added reactance in the bus, a short-circuit value of current in a feeder figured in this manner would lead the uninitiated to select a breaker costing, say, $\$ 500$, when actually a considerably cheaper breaker, with one or another of the multitude of standard reinforcings will meet the conditions. Thus, we find a manufacturer carrying in stock, say, twenty-five different varieties of a single type of circuit breaker, because the consumer has imposed at least this number of operating conditions which the manufacturer must meet if he is to make a sale and keep the business. Each time the manufacturer has sought a new way out of his dilemma by devising a new variety of reinforcing, or a slight change in design which will enable him to get away with the sale. And, withal, he probably takes a chance at that-a chance that will most hurt the consumer if the dice fall the wrong way.

This sort of thing results only in harm to all parties concerned. It works an undoubted hardship on the manufacturer, for in time the cost to him of maintaining so many standards, any one of which may have relatively few sales a year, becomes prohibitive. This means more capital invested, and when we get right down to brass tacks it is the consumer who invests his own capital in the manufacturers' stock room. The term "stock room" here covers a multitude of sins.

In a paper recently presented before the Schenectady Section, I drew attention to the economy both to consumer and manufacturer that could be achieved by "Standardization of Demand" in the special case of the low-tension distributing systems in industrial plants. The same remarks apply in a broader sense to distributing systems of all kinds. The distributing system is to be considered as including everything engaged in carrying energy from the generator to the point of conversion or utilization-switchboards as well as transmission equipment.

The problem of "Standardization of Demand" is obviously up to the consumer and his advisers rather than to the manufacturer.

Fred C. Hanker: The rating of circuit breakers has been specified as the highest r. m. s. current that can be interrupted under certain conditions. It is this basis of specifying rupturing capacity which makes it necessary to determine the value of the short-circuit current before the breaker can be properly selected for a specific application.

The authors have given in Figs. 2 and 3 a series of curves for various values of total system reactance. They have, for convenience, tabulated these data.

With this information it will then be possible to properly apply a given breaker, after the method of tripping and the value of feeder reactance in the system is determined.

The elapsed time can be ascertained with accuracy once the method of tripping is adopted and the speed of the breaker 
is specified. Furthermore, the reactance of the system can be calculated from the characteristics of the apparatus under consideration.

This, then, leaves the short-circuit transients of the system to be determined in one of the ways outlined by the authors, so that the value of the r. m. s. current at the time of opening the breaker can be secured.

Obviously, from the number of factors affecting this characteristic, it is not a simple calculation, and it is always debatable whether all of the variables have been given proper weight or consideration. Even granting the ability to predetermine this characteristic, the best criterion of its accuracy is a check against actual results obtained from oscillograph tests.

The curves as given in Figs. 2 and 3 , showing the relative values of r. m. s. current in terms of the total full-load current of machines, and under short-circuit conditions, check, reasonably well, the r. m. s. current values determined from actual oscillograms taken on a-c. generators when short-circuited at full voltage. After the first fraction of a second following short circuit, the actual curves fall slightly below the proposed curves, due to the fact that the oscillograms were taken for short-circuit conditions at no load, and full voltage, whereas the proposed curves are based on full-load conditions, at 80 per cent power factor.

From this check it is the opinion that the curves are satisfactory and represent with safety the short-circuit currents on three-phase short circuits that may be expected from normally designed generators.

The curves that we used in making this check covered a wide variety of apparatus, as they included both high-speed turbo-generators as well as normal speed and low speed waterwheel machines. They do not take into consideration extreme power factor operation, as this has been specified at 80 per cent in the paper. Obviously, for lower power factor operation, where greater excitation is required, the sustained short-circuit values may be somewhat higher. These cases are rather rare, and would be taken care of without difficulty if they are once specified.

Another point is in the sustained value as given in the curves. They cover a certain range in values as given at three seconds. If the machine alone had been considered it might have been preferable to construct the curves on the basis of a given sustained value, but when you take into consideration the external reactance which occurs in all cases, probably above 15 per cent or 20 per cent, and in a large number of cases above 10 per cent and 12 per cent, that sustained value would be different for different conditions.

Philip Torchio: The subject of the selection of circuit breakers of large rating is of relatively great importance in but a few instances where the plants have very large capacity, and, as the 
authors have specified, on such occasion a special study must be made jointly and in cooperation between the manufacturer and the user.

I shall not refer to that type of circuit breaker, except by making a general statement that as far as I know we have not today available a circuit breaker of sufficient capacity to open the short circuits on our larger systems with a short circuit in proximity to the generating stations. In such instances limiting reactances have to be used to confine the "short" within the rupturing capacity of the circuit breakers available.

In the development of the circuit breaker, we have apparently attempted to follow the example of the man who plays his fiddle by main force. We are forcing our circuit breakers to do all the work, and probably we are expecting too much in that direction; still, it is wise to keep on studying the problem, in the hope that some day we will find a circuit breaker that will be of unlimited rupturing capacity.

When it comes, however, to the general use of circuit-breakers -which represents 95 per cent of the circuit-breaker applications-for those cases the paper before us is applicable, and is a step in advance, and should be followed up by further standardization, so that, as some of the previous speakers have already pointed out, the user could more readily get at the values of the ratings of the circuit breakers offered by different manufacturers.

I also want in this connection to give a note of warning with reference to following out the suggestion in the paper that if we select a certain circuit breaker for certain existing conditions, we must remember that the conditions of the supplying electric systems change very materially with the growth of the system. The man who makes a selection must also have a view into the future, and not be guided only by what the conditions are today, or what he expects next year, but he should possibly foresee what the conditions may be in several years.

In my personal experience, I find that many times we are confronted with a proposition that today could be handled with a certain circuit breaker, which is relatively cheap, say costing $\$ 300$. If we could foresee the conditions which will probably prevail three or four years from now, we would see - that that circuit breaker should either be supplemented by a limiting reactance or a larger circuit breaker used. In a great majority of cases you will find that the larger circuit breaker is more economical than the combination of the small circuit breaker and the limiting reactance.

In customers' installations, it may be, however, impracticable to put in the larger circuit breaker-as, having only one circuit breaker on the premises, it would be preferable to avoid the operation of a complicated mechanism. The mechanism that would be perfectly feasible in the substation of an operating company might not be so in an industrial plant or on customers' 
premises. In that case the limiting reactance, in combination with the small circuit breaker, in many instances, while it may be more expensive in first cost, I believe will be found to be preferable. If you take such point of view, broadly you will standardize the circuit breaker, and you will not have so many circuit breakers to select from.

Referring specifically to the paper, where it is stated-“A1though not stated in rules, we infer that it contemplates a test with the apparatus under dry conditions." I imagine that the outlines mean that it was filled with oil, in accordance with the Standardization Rules of the Institute. The wording is not entirely clear to me as to what the dry condition means.

Referring to paragraph, "The breaker interrupting capacities in r. m. s. amperes published by various manufacturers are based on an assumed duty, $i$. e., that the breaker will interrupt its rated r. m. s. current two times at a two-minute interval and then be in condition to be closed and carry its rated current until it is practicable to inspect it and make necessary adjustments." I suppose it is assumed that also it is in position to open the circuit a third time. That was our understanding - that is, when closed, it would be still in a position to open.

J. M. Mahoney: Open mechanically, but not automatically, under the same conditions.

Philip Torchio: Quoting again, "Systems having characteristics such that the reestablished pressure during short circuit will be higher than normal, will require a larger breaker," refers to circuit breakers at the ends of long distance transmission lines.

In reference to the dying away of the transient current in the direct component of the current-at least mention might be made-that in a system where they operate without Tirrill regulators, but with rheostatic control in the field, the rheostat resistance in series with the field would tend to accelerate the dying out, because it absorbs more rapidly the energy that is dissipated while in places where the Tirrill regulator is used, with less resistance in the field, probably there would be slower dying out.

In the section referring to the guarantees and heating in a general way we must depend on the manufacturers to arrange the guarantees, but I think there ought to be more co-operation, to get a little more uniformity, so that the user can have clear before him information for the selection of the circuit breakers needed.

Paul M. Lincoln: I want to call attention to one paragraph which is particularly interesting to me, it is that referring to the classification of systems, in which the authors say: "Systems may be classified according to their normal operating pressure, normal current, normal frequency and current transients." It is that last item, the "transients" that is the unknown quantity 
in this classification. It was absolutely unknown to me at the time I entered the operating business some twenty five years ago with the Niagara Falls Power Company. In perfectly good faith, when we came to figure our short-circuit currents at that time, we figured the currents we were going to get on short circuit were the same we got on the short-circuit test made in the test room, and which amounted to two or two and one-half times the normal full-load current. When we got short circuits in practise we found evidence of the fact that the currents were not limited to two or two and one-half times full-load current but were many times that. Such things as the tearing apart of the windings, the breaking of windings, the throwing of cables around the power station, and similar things, gave evidence that the currents were not limited to the two or two and onehalf times full-load current that we expected, and it was then that this question of transients began to have a real meaning for us.

Our knowledge of what transients are has, of course, increased in the time between that experience, back in 1896 and 1897, and the present time, but I think even yet there is much we have to learn about the matter of transients.

The authors speak of the use of reactances, and there is a more or less indefinite term used in connection with the rating of reactance. Reactances are usually rated in percentages of the normal voltage, but it is not often stated how much current these reactances are supposed to carry for that given stated percentage of reactance voltage, and the stating of that current is an absolute essential in the rating of the reactance. The percentage stated in terms of the normal carrying capacity of the reactance, or in the normal carrying capacity of the apparatus back of the reactance or in some definite manner is an absolute essential in arriving at the rating of any reactance.

On this question of the rating of circuit breakers, let me say that the manufacturers are at all times giving to the user of these circuit breakers the best they have. Whether or not the best they have is good enough to take care of the job of the user, there is only one way of determining and that is by trial.

As Mr. Hewlett pointed out, it is impossible for the manufacturer to go to the user of the apparatus, particularly if the user is on the order of $100,000 \mathrm{kw}$., or more, and ask him for the loan of his plant for the purpose of testing circuit breakers.

That is out of the question, because the user of that apparatus is not justified in taking the risk which would be involved in the testing of the circuit breakers under the actual operating conditions. As a consequence, the manufacturer must get his information for designing circuit breakers by the observation of short-circuit conditions that occur, and he must gather that information as it is presented to him from time to time. Consequently the question of just what breaker is necessary, just how big it should be, how much oil to use, and all those things 
that are necessary to take care of given conditions, particularly when those conditions approach the limit of existing plants, must necessarily depend upon the closest possible cooperation between the manufacturer of the apparatus on the one hand and the user of the apparatus on the other. It is only by that kind of close cooperation between the two that the question can be ultimately worked out.

R. E. Doherty: I should like to make some comments that may be useful in applying the curves shown in Figs. 2 and 3. There is a large difference between the sustained short-circuit current of generators which were built 10 or 15 years ago, and those which have been built in more recent years. These curves show sustained values which correspond approximately to the maximum that would be found in machines which have been built during recent years by one of the manufacturing companies, whereas for older machines the curves show values which are more nearly representative of the average. That is, the older machines may have higher sustained short-circuit currents than indicated by the curves, and should therefore be treated as special cases.

It may be of interest that the difference between the old and the more recent generators is largely the result of the introduction of the automatic voltage regulator. Before the advent of the regulator, generators were required to have good inherent regulation, that is, low armature strength, relative to the field strength. That means high sustained current. With regulators, this restriction is removed, and for reasons of economy the armature is made stronger, which means lower sustained current.

Fred L. Hunt: It is not understood, that the authors have suggested any more definite means of rating circuit breakers than has already been done by the rules and practises to which they refer. Operating engineers will find all the information and data given in this paper to be most valuable and highly practicable, but it is believed that these engineers desire very much to have a more definite method of rating circuit breakers, presented. Nothing, so far as is known, which is now published by the manufacturers would enable the operating engineer to choose from the published data a circuit breaker suitable for one of the definite conditions outlined in the examples in this paper, assuming that he had the information regarding his own system shown in the examples.

Under present conditions the operating engineer must leave entirely to the manufacturer the question of deciding what circuit breaker is suitable for his particular conditions, without having any means of determining how well he has met the requirements specified, or of comparing the factors of safety which may be allowed by different manufacturers in their recommendations for the same switching requirements.

All will probably agree that the manufacturers are well qualified to recommend the circuit breakers that should be used for 
any given set of conditions, but if circuit breakers are to be put on anything like the same basis, so far as comparative ratings are concerned, as is now the practise with other electrical apparatus, in order that operating companies may have an independent means of comparing the recommendations made by various manufacturers, and of testing under a fixed set of operating conditions the apparatus produced by various manufacturers, a system of ratings should be established which would be definite with regard to all the conditions which are pointed out in this paper as affecting the rupturing capacity of a switch.

Eight items are mentioned, all of which affect the current flowing to a short circuit at any point in a system. This does not mean, however, that there are necessarily that many different interpretations of a given rating for the rupturing capacity of a circuit breaker.

It is suggested that the manufacturers set down a definite rupturing capacity for a given switch, describing in as much detail as they choose the exact conditions upon which the rating is based, and that they then furnish curves or other data which will show the variation of this rupturing capacity due to-

First: Variation of the re-established bus voltage.

Second: Variation of power factor of the current flowing into the short circuit.

Third: Variation of the ratio between generator reactance and line or system reactance.

Fourth: Variation in the total capacity of synchronous equipment connected to the system.

Fifth: Variation due to nature of the short circuit, whether single-phase, three-phase, or between one phase and ground.

This will then leave to the engineer who applies the circuit breaker the duty of determining the transient characteristics of his synchronous machines, the time setting of his relays, the total impedance of his circuits leading to the point of short circuit, the resistance of the short circuit, the power factor of the load being carried at the time of the short circuit, and the bus voltage to be re-established after the opening of the circuit.

The data suggested above to be supplied by the operating engineer could all be obtained from other sources than from the oil switch designer.

Some such system of rating as that suggested above is required in order that operating engineers may be able to select switches for their circuits in the cases at least of all systems which do not come under the heading of "average systems", and it seems reasonable to ask the manufacturers to supply such information. It also seems desirable that the authors of this paper should define what is meant by an "average system".

The writer has recently had occasion to study switching capacities for a system in which a switch in one substation is apparently required to open a short-circuit current of approximately $40,000 \mathrm{kv}-\mathrm{a}$., whereas a switch in another similar sub- 
station not far away is required in the case of a short circuit to open $145,000 \mathrm{kv}-\mathrm{a}$., and at another substation short-circuit conditions may require the opening of $270,000 \mathrm{kv}-\mathrm{a}$. It would be interesting to know whether such a system would be considered an "average system".

Herbert H. Dewey: It is gratifying to the transmission engineer, to know that we have reached the point where we are talking about the same kind of amperes. If now we accept the fact that the circuit breaker designers have chosen the ampererating in rupturing capacity that their switches are good for, it is up to the power and transmission engineer, the man who makes the practical application of these switches, to determine how much cur rent we have to rupture in a given case.

Some points in connection with determining this current have always been somewhat uncertain. We obtain from the manufacturer the reactance of the generator, transformer, etc., usually in per cent, and we know that a ten per cent reactance generator will give ten times normal current on short circuit. It has never been definitely understood by us all however what this ten times normal current is. One man suggests that it is ten times normal symmetrical, and it may be double that. The paper discusses the different values of current obtained on short circuit and defines the current to be used in determining the duty imposed on an oil circuit breaker as the r. m. s. current at the time the circuit breaker opens. The application engineer must determine the r. m. s. current at the point of short circuit by some suitable method.

On simple systems, which the paper purports to cover, that is an easy proposition. It is merely a question of adding up the reactances in series or multiple, as they occur on the system. When we have obtained the final result we have a reactance of, say, twenty per cent on the rating of the total generating capacity, and by referring to our curve we find that we get so many r. m. s. amperes at a given time.

The next point to determine is how soon the circuit breaker is to open. That will be a pretty definite thing because of its location. We use certain relays that must be selective. We use on the generators, as a rule, non-automatic switches. If we have to choose a generator switch, we consider the time it will take for the operator to open the switch, which means constant value of current. If we have a differential relay, which is expected to open the generator circuit in case of breakdown of the generator itself, that means we have a very quickoperating relay, so that the duty on the circuit breaker would be quite different in the two cases.

$\mathrm{Mr}$. Torchio and Mr. Lincoln pointed out that we are going to have very great increases in the capacity of our systems, and it is increasingly important that we have some definite method of determining the amount of short-circuit current that will flow to a fault. Existing stations have grown away beyond 
their original capacity as planned, and existing systems have tied in with other systems, so that we are getting enormous blocks of power concentrated within short distances.

The increase in the capacity of circuit breakers necessarily has gone up by leaps and bounds, and we hardly know where it is going to stop. As a matter of fact, it would seem as though there were some possibility of reaching a limit, that is not that of the rupturing capacity of the circuit breaker. It is, of course, possible to build circuit breakers of enormous size, and it is conceivable that we could reach practically unlimited capacity in the circuit breaker, one that may be large enough and strong enough for any situation. It is probable there will not be a demand for this, on account of the damage done at the point where short circuits of these enormous capacities are concentrated. We have ruptured, perhaps, $500,000 \mathrm{kv}-\mathrm{a}$. up to the present time. We have found the bus bars pulled from their supports, the cables damaged, pulled off the wall, and great damage done in other ways outside the circuit breaker itself, so it is probable that these features will be limiting ones, rather than the extreme rupturing capacity of the circuit breaker.

There is another point in answer to Mr. Hunt's question, as to what the scope of these curves is, or, in other words, what is an average system. The authcrs have put down in this paper examples of what they consider average systems, and you will notice they are all confined to one generating station. When we come to deal with a number of generating stations we get into complications in calculating the current involving the use of Kirchoff's Laws which make the problems very difficult. We have in our department in the General Electric Company in Schenectady a calculation device which will take into account the distribution of current between stations and that makes it very simple to solve a problem of this kind. It is practically the only way it can be done, because with several generating stations the apparent reactance of each line is modified by what is coming in from others, and it is diffcult to obtain the direction of flow of current in each individual circuit. By the use of apparatus of this kind, the tables and curves given in the paper would become universal, and any one could calculate to a fair degree of accuracy the short-circuit current on practically any complicated network.

H. D. James: I wish to call attention to this statement, "These factors are of special importance when a breaker of relatively small interrupting capacity is connected to a large system in such a way that the breaker may afford the only outlet for the stored energy of the system." It is very proper that this discussion should have been confined largely to breakers applied to large systems that had large capacities behind them. However, a very large class of applications are for the protection of electric motors, and come in a class of smaller breakers. Ninety to 95 per cent of such applications are limited by the distributing transformer, so that the power is limited. 
There is danger of trouble, however, in power stations, and other large installations, where the power behind the breaker is large. This is particularly true where the overload protection is included as part of the control equipment. One way of taking care of that is to introduce a time element in the overload capacity of the control equipment or breaker protecting it, so that the feeder breaker will take the load. Unfortunately, the feeder breaker also has a time-element introduced in many cases, so that care must be taken to see that the time-element protecting the motor from overload is longer than the timeelement of the breaker back of it, if the power is greater than the circuit breaker capacity of the control equipment.

N. L. Pollard: The paper presented contributes a great deal toward clarifying the determination of system rating, but does not assist in the selection of proper oil circuit breakers to meet these conditions, even after determining them.

The sections of the Standardization Rules covering the rating of oil circuit breakers are very indefinite, and do not in any way assist in a selection, unless supplemented by further information furnished by the manufacturer, as recommended in the closing paragraph of the paper under discussion. Such information has been entirely omitted from the paper, although it is a well-known fact that extensive tests covering rupturing capacities of various types of breakers have been made.

This subject is of such vital importance to the profession that further investigation seems advisable, and I would therefore suggest that a committee be appointed, composed of operating as well as manufacturing engineers, who should attack the subject from the standpoint of determining the relative merits of the various design factors. These factors should then be given definite values with regard to the rupturing capacity of the breaker and the results tabulated and embodied in the Standardization Rules.

The maximum rupturing capacity of the oil circuit breaker in amperes at rated voltage, should be stamped on the nameplate, in addition to the normal rating.

E. G. Merrick: The typical curves given in the paper are based on three-phase short circuits; the results are sufficiently accurate also for single-phase conditions if instantaneous values are considered but cannot be applied in all cases to sustained current calculations.

If a Y-connected, three-phase alternator with perfect "damper" is short-circuited successively across three terminals, two terminals and one terminal to neutral - the excitation remaining constant - the sustained currents will be approximately in the ratio of 100,175 and 300 . These values are modified more or less depending on the extent to which the single-phase armature reaction is annulled by the damping action of the field, so that for a standard salient-pole machine without amortisseur winding we find that the currents are in the ratio of approxi- 
mately 100,130 and 200 and for a salient-pole machine with amortisseur winding, or for a turbo-alternator with solid forged rotor, they are in the ratio of 100,150 and 250 . That is, in the former case, the single-phase short-circuit current will be 1.3 to 2.0 times the three-phase value and in the latter case 1.5 to 2.5 times-the excitation remaining constant.

The single-phase values for short circuits between terminal and neutral can in general be disregarded, in view of the fact that where several machines are operating in parallel, it is customary to solidly ground the neutral of one generator only, or if all machines are grounded, to parallel the individual neutrals through grounding resistances.

If the short circuits occur on the line side of a transformer in series with the alternator, the single-phase values of sustained current, with constant generator excitation, are again different from the three-phase values, the magnitude of the difference depending on the ratio of sustained generator reactance to transformer reactance and also whether the transformer is connected delta-delta or delta-star. These values may again be considerably modified if the transformer is feeding a transmission line whose characteristics are such as to give high values of charging current for the single-phase conditions.

Although the single-phase values of current may be, in certain cases, greater than the three-phase values, it does not necessarily mean that the switch duty has been increased. If the single-phase short-circuit occurs between terminals of generator or transformer, the higher value of current is more or less compensated for by the fact that there are now twice as many active switch contacts in series (charging current neglected).

In view of the usual margin of safety in oil circuit breakers and the fact that they are generally set to operate before sustained conditions are reached, their selection can ordinarily be made on the basis of three-phase values of short-circuit current. The sustained condition is important, however, in certain cases and should be made the subject of a future contribution to this subject.

P. H. Adams: Does this paper bring us any nearer to a uniform method of rating oil circuit breakers than we were a year ago? The operating engineer can determine his shortcircuit current values, either by test or calculation, but on what basis can he select the oil circuit breaker for rupturing this current? There are on the market today, oil circuit breakers with fanciful ratings, having tin cans for oil tanks. How can we discover the truth in regard to our oil circuit breakers when such conditions exist?

There are ten or more well-known factors entering into the design of an oil circuit breaker, which govern its rupturing capacity. Modesty has apparently prevented the authors from touching this side of the question, therefore I agree with $\mathrm{Mr}$. Pollard, that a committee should be appointed to investigate 
this matter further and if possible, assign definite values to these design factors from which the rupturing capacity may be determined.

The rupturing capacity in amperes at rated voltage should appear on the name-plate of each oil circuit breaker, and the circuit breaker should rupture this current two times at a one minute interval and then be in condition to be closed and carry its rated load until it is practicable to inspect it and make necessary adjustments, without regard to generator or bus capacity.

If this condition cannot be met, then the Committee should divide oil circuit breakers into several classes, based on generator capacity and clearly define the design factors governing each class.

This is the kind of information the operating engineer desires and is what the title of this paper would lead one to expect to find outlined in it. I thoroughly agree with the closing paragraph of the paper that manufacturers should publish more information on the subject but this will be of little value unless the Institute adopts a standard of comparison. It is disappointing to hear Mr. Hewlett say this is the kind of information we cannot get.

Ira M. Cushing: The authors start in by speaking of normal pressure, normal frequency, and all conditions are normal until they begin to talk about the duty of the circuit breaker, and then all conditions become extremely abnormal.

It seems to me the circuit breaker has two, if not possibly three duties to perform. First, it is a device for disconnecting a circuit, or possibly disconnecting the apparatus. That is a very important duty, and in connection with that duty is the second one, namely, the ability to carry normal current. Then there is the third duty, that of opening a circuit under abnormal conditions.

I believe that this paper, to an outsider or possible purchaser of oil circuit breakers, is almost an alarmist paper-he would mentally throw up his hands and say- "I don't dare have one on my system." Therefore, I think this word "duty" should possibly be modified, or there should be a paragraph or two added to the paper, describing what the oil switch or oil circuit breaker should do, besides the opening under abnormal conditions.

Possibly the words "prescribed conditions" are not well chosen. We should use the word "abnormal conditions." You speak of prescribed things as something you expect might happen quite frequently, but when you come to speak of abnormal conditions, then you are looking for something that is different, and that is, of course, what is spoken of in the paper.

At the end of the paper the authors practically nullify the entire thought by admitting that everything that has gone before covers systems that do not have voltage regulators. It 
is my impression that many systems have voltage regulators, and especially systems that have a large lighting load, and for that reason it would appear to a person, not familiar with the apparatus, that the figures given would not apply at all to the average system.

J. N. Mahoney: Mr. Torchio mentioned the probable condition of the apparatus after it performed the duty specified. One of the well know disturbances presented by an oil breaker in operating under near maximum conditions, is to throw some oil. It is self-evident that if the amount of oil thrown is great, it limits the ability to take care of the next successive operation of the breaker. As a matter of fact, that is one of the points that is a controlling feature.

The breaker may open twice, undertaking the maximum duty for which it is guaranteed, and the oil level may be so reduced that if operated a third time you could not expect to get the same standard of performance, as in the first instance. You might operate it at a smaller power duty, and so on down with each successive operation, and in this way you could operate it successfully a large number of times; the first time at the maximum. With a sufficiently small power duty, the breaker might be made to operate indefinitely even in its depreciated condition.

The breaker blowing off a tank, breaking a tank supporting frame, or causing an unusual mechanical destruction of some other kind, is not contemplated as being within the accepted practice, or definition of successful "two-time operation."

The second point in the depreciation, you might say, of operation, is the arcing "tips", or the contacts forming the arcing members. While the conducting contacts may not be injured, the arcing contacts may be consumed considerably. Therefore it is undesirable to operate at the maximum duty any more than a given number of times, until the circuit breakers are inspected and repaired. The device may be closed again, and service maintained for an indefinite period, that is, until the normal inspection period. That contemplates, assuming the breaker is an automatic one, that if it is subjected to two successive maximum operations as stated in the guarantee, the breaker would be made non-automatic after the second operation. It will then be just a conductor, or disconnecting switch, and the automatic protection will be afforded by other means in the circuit. Usually, as Mr. Hewlett remarked, it may be that destruction beyond the breaker, caused by the short circuit gives you all necessary time, even after one operation, to readjust the breaker, before it is necessary or desireable to close it.

The question has been raised by several of the speakers, as to what constitutes an average system. It simply means an average radial system, as practically all general service systems are. Such a system does not have its load in one block, with 
a single controlling breaker. The difference is not because of any condition of power factor in the system, but the fact, in the single breaker system, there is practically but one outlet for the stored energy, that is the breaker itself. I think that will clarify the situation.

Philip Torchio: The point I make I think is rather important: After the second closing, if you require the breaker to do some future interupting work, - do not close it, but leave it there for the normal inspection. Its condition is that it is not immediately capable of opening against its rated powers.

J. N. Mahoney: That is the understanding.

Chester Lichtenberg (communicated after adjournment): The rating and application of oil circuit breakers requires an intimate knowledge of the phenomena taking place not only in the external electrical circuit, but also in the breaker. It is essential to understand not only how a circuit behaves under transient electrical conditions, but also how the oil circuit breaker performs its energy dissipating and circuit interrupting functions under these conditions.

Consider an oil circuit breaker. It consists essentially of a pair of separable contacts immersed in an oil bath. Suppose this simple breaker to be connected in an a-c. circuit carrying a steady current at a steady pressure and steady power factor. Now assume the breaker contacts to part, and to continue in motion with approximately constant velocity until the circuit shall have been interrupted.

Under these conditions it is found that when the breaker contacts part, an arc is formed. This arc gasifies that portion of the oil in the immediate neighborhood of the contacts, and a spherically shaped globule of gas is formed around them. The pressure in the globule depends on the amount of energy which the breaker is called upon to dissipate, and under extreme conditions it may become as high as several thousand kilograms per square millimeter.

One effect of the pressure in the gas globule is to raise the level of the oil in the bath. It is for this reason that all well designed oil circuit breakers have a so-called "air buffer" between the top of the oil and the oil vessel cover or lid.

As the contacts move further apart, the arc lengthens, and due to internal pressure, the gas globule grows larger. The globule retains its spherical shape, though until the contacts move out of it, or it encounters the side walls of the containing vessel.

When the moving contact passes out of the gas globule, the arc follows, and a path is provided for the relief of the pressure stored in the globule. This causes the globule to burst explosively, and by this action the arc is blown out and oil tended to be ejected from the vessel.

In the interruption of most electrical circuits this is the only action that occurs during a successful operation of the breaker. In the interruption of some circuits, however, there is an added 
step. The bursting of the first globule, initially surrounding the contacts, is followed by an elongation of the arc through fresh layers of oil, and the formation therein of new gas globules having, however, much less internal pressure than the first. These new globules burst in turn without interrupting the circuit, till finally one of them succeeds in blowing out the arc and interrupting the current flow.

The formation of gas globules, their subsequent enlargement, distortion, and bursting are shown in Fig. 1. This photograph was taken with the successive image camera described in a previously contributed discussion. It is typical of hundreds of photographs which have been taken and studied. The arc images represent exposures made at intervals of about 0.005 second. The first image is at the right end of the lower row. The second, third, fourth, and fifth are adjacent to it on the left in the order named. The sixth is at the right end of the lower but one row. The seventh is at the left of it. The twelfth is at the right end of the third row, and so on. They show quite clearly the different stages in the interruption of a current carrying electrical circuit by an oil circuit breaker.

The bursting of the gas globules when an oil circuit breaker is clearing a circuit, is followed by external evidences of distress. Some of these are as follows: (1) Dull thud; (2) Ejection of oil; (3) Ejection of flame; (4) Straining or bursting of oil vessel. The circuit interruption is also indicated to have taken place explosively by oscillograms contributed in previous discussions. These show that the current is diminished with increased rapidity as the interruption progresses, successfully, until the end is approached with great suddenness or abruptness.

This explosive interruption of the circuit has a very important bearing on the application of oil circuit breakers. As I pointed out during a previous discussion, and as is stated in the paper, not only must the characteristics of the circuit to which a breaker is to be connected be known, but also the characteristics of the breaker itself must be known. The explosive action of the breaker introduces an element of wide variablity in the operation of the breaker, and makes it difficult to predetermine its performance with great accuracy.

It is a well known fact that the characteristics of generators, motors, transformers, transmission lines, and other parts of electrical circuits may be determined by test and calculation quite accurately, $i$. $e$. within 2 or 3 per cent. It is also a fact, though not nearly so well known or recognized, that the performance of an oil circuit breaker cannot be predetermined with an accuracy closer than 15 per cent. This fact requires especial emphasis at this time since many incorrect breaker applications are made because a knowledge of the limits of accuracy of the calculation of systems and breakers is not general.

The limit of accuracy of the predetermination of breaker ratings is an important item at this time also because the paper 
PLATE I.

A. I. E. E.

VOL. XXXVII, 1918

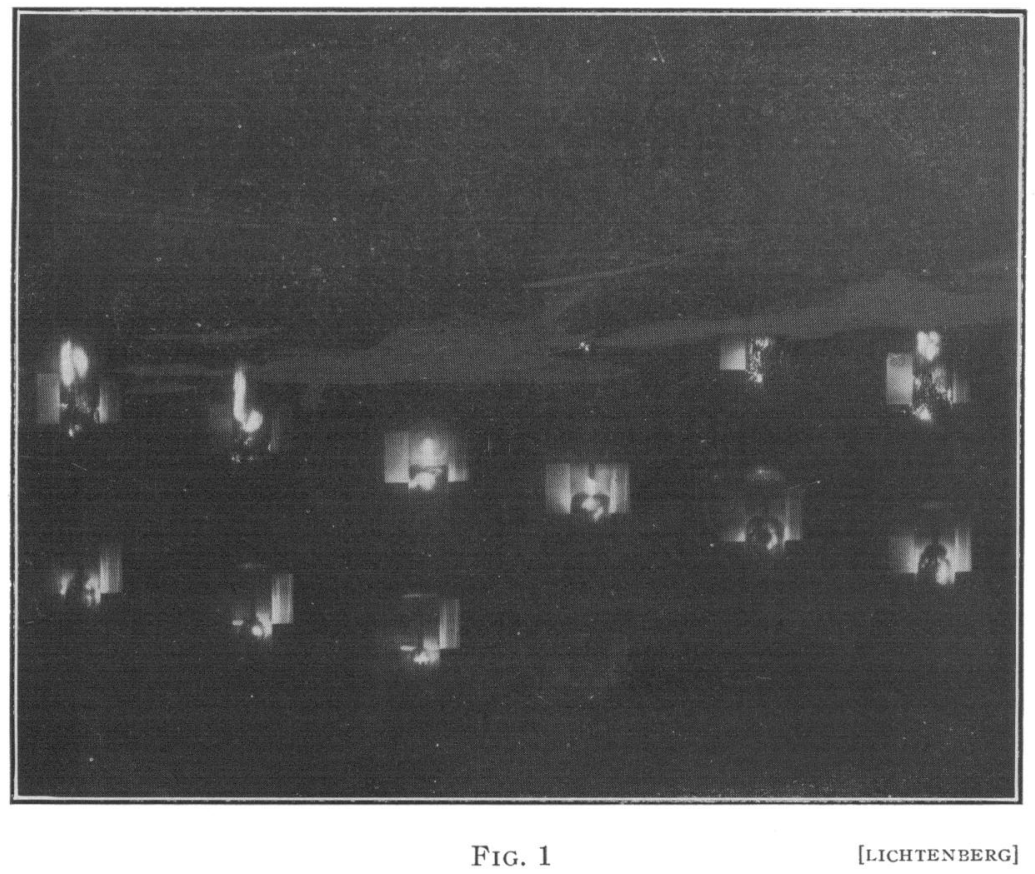


under discussion proposes rules for the rating and application of these devices. These rules have been derived from an analysis of a large amount of data accumulated during over twenty years of experience. In this, the proposed circuit breaker application rules follow the precedent established in the development of empirical rules for the calculation of other electrical machines. The great difference is, though that whereas most other electrical machines and devices are calculated for ordinary or steady circuit conditions, the oil circuit breaker interrupting capacity must be computed for extraordinary or transient circuit conditions. Therefore, while apparatus for steady conditions can be built to within 2 cr 3 per cent of the design calculations, oil circuit breakers frequently have interrupting capacities more than 50 per cent outside the design calculations.

One other factor requiring attention is the application of breakers to growing systems. A breaker has a finite capacity, while compared thereto the ultimate capacity of the system may be infinite. The limitation of the breaker, while known, is not always taken into account as the system grows. Finally a point is reached in the expansion where the breakers are quite inadequate and a failure results. The possible future growth of a system should always be considered at the time the breaker equipment is planned, and while it is not recommended that the initial installation of breakers be suited for the ultimate development, it is suggested that the arrangement of units be such that if the system grows beyond the limits of the circuit interrupting equipment initially installed, this may be moved to other parts and replaced by larger breakers with a minimum of expense.

A. Collins (communicated after adjournment): It would be of interest to know whether the authors are of the opinion that the factors suggested should be increased if a tr.ree-phase generating plant is short-circuited across one pair of phases only, as this may have some bearirg on the breaking capacity of switches in which a separate tank is employed for each phase.

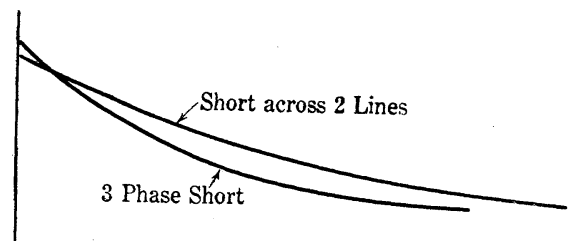

FIG. 2

The curves given are presumably based on three-phase short circuits, and it would be expected that although the shortcircuit current across one pair of phases is actually about 13 per cent less than the three-phase short-circuit current, owing to the decreased armature reaction, the resultant field will decay 
less rapidly, thus producing characteristic curves with a more gradual slope, see Fig. 2.

Under the heading of "Precautions" there are one or two other factors which may tend to increase the stress on the switch which has been selected by the use of the data provided.

It is conceivable that a high resistance fault may be sufficient to operate the protective gear, and energize the trip coil, and that this fault may develop into a dead short circuit at the instant the switch contacts separate. With maximum assymetry, or as the authors describe it, maximum possible direct component in the short-circuit characteristic, the current at the instant of break will be much greater than that given by the figures in Table 1; for example, with 10 per cent reactance the peak value of the short-circuit current would be 20 times the peak value of the full-load current, and the ratio of the r. m. s. values would be approximately of the same order.

In addition there is the doubling effect in transformers and reactance coils, resonance and other phenomena.

It is important that switches, particularly those near to the generating plant should be selected for the most severe conditions that may reasonably be expected, but I should like to hear the authors' opinion as to how far they consider provision should be made, if any, for such contingencies as those just mentioned.

Charles C. Garrard (communicated after adjournment): There can be no doubt that, at the present time, the circuit breaker forms a limiting feature in the construction of very large power stations. The application of power limiting reactances has rendered the super-power house possible. Such reactances are, however, costly and, in themselves, undesirable pieces of apparatus. The lower limit of size above which reactances are necessary is fixed to a very great extent by the safe rupturing capacity of the oil circuit breakers; the higher this is, then the greater may be the capacity of the power house without the addition of the reactance coils.

This subject is at the present moment occupying the attention of the standardizing authorities in this country. A conference dealing with it was held recently between Mr. H. M. Hobart representing the American Institute and representatives of the Institution of Electrical Engineers, the British Engineering Standards Committee and the British manufacturers. In addition a committee of the manufacturers themselves has the matter under consideration, and it is hoped that this committee will be able before very long to publish the results of its deliberations. The following remarks, in the meantime, are made in the writers' personal capacity.

In the first place as regards the pressure test I am not quite certain what is meant by "dry conditions;" I presume it is intended that the insulators should be free of moisture but that the oil tanks should be filled to their normal extent with oil. If so I am in agreement, unless of course the circuit breaker is for 
out-door service in which case the test should be taken under rain-conditions.

I think the limit of temperature rise of contacts in air of 20 deg. cent. (ambient 40 deg. cent.) is too low. For large apparatus especially, it is difficult to work with such a low limit, moreover I can see no reason at all for such a small figure. I think $30 \mathrm{deg}$. cent. is quite safe. Again the temperature limit of $70 \mathrm{deg}$. cent. for oil is unduly conservative for large current circuit breakers. This limit might be retained for sizes up to and including 2000 amperes; above this however a temperature rise of the oil of $40 \mathrm{deg}$. cent. is not unreasonable. The temperature should be measured at the top of the oil.

The most important point of the whole discussion is of course the rupturing capacity. It follows from the authors' arguments that a rating in terms of rupturing current is recommended. In this the authors agree with the German standardizing authorities. The original V. D. E. suggestions for the rating of oilcircuit breakers proposed a kilovolt-ampere rating (see E. T. Z. $16-2-11,1911$, page 171), but this was afterwards changed to an ampere one. There are, however, very considerable advantages in the adoption of a kilovolt-ampere rating. Really, of course, there is no essential difference between this and the authors' system. The ampere rating is simply converted into the kv-a. rating by multiplying by the rated pressure and the factor 1.73 and dividing by 1000 . For rapid calculations, however, and for the comparison of circuit breakers on different voltages, the $\mathrm{kv}-\mathrm{a}$. rating, in the writer's opinion, is the better one. There can be little doubt that, probably without introducing any error greater than that inherent in the underlying assumptions made by the authors, that the $\mathrm{kv}$-a. rating (rupturing capacity) of a given breaker is independent of the voltage. Thus the same circuit-breaker (if the insulators be suitable) may be used either on a 6000 or a 3000 -volt circuit. With the ampere rating it would be necessary to give this one circuit in such circumstances two different ratings for its rupturing capacity which would be likely to cause confusion. Moreover, to the present writer, it seems more logical to rate in terms of $\mathrm{kv}-\mathrm{a}$. It is after all the power flowing which is ruptured. It is the absorption of power within the circuit-breaking device over the time taken for the rupture, $i$. e e the total energy absorbed in the oil, which does the damage. The theoretically correct rating would therefore be in kilowatts rupturing capacity; this, however, introduces questions of power factor etc., as to which no exact statement can be made. It seems, therefore, that the kilovolt-ampere rating is the best under the circumstances. Certainly in this country the present tendency is towards this conclusion.

As regards the prescribed duty I am in agreement with the suggestion that the breaker should interrupt its rated rupturing current (or, as I prefer, its rated $\mathrm{kv}-\mathrm{a}$.) twice in succession, and 
then be in condition to be closed and carry its rated current until it is practicable to inspect it and make any necessary adjustments. I do not think however a two-minute interval should be called for between the two operations; it should be allowable that these should follow each other rapidly as this is in accordance with practical operating conditions.

The definition of breaking capacity, therefore, which I would suggest is as follows: "The breaking capacity of an oil circuit breaker should be given in kilovolt amperes based on the rated pressure and the current at the instant of break. The rating of an oil circuit breaker shall be the maximum kilovolt amperes the circuit breaker will break twice in succession, and after this be capable of carrying normal current."

The curves and examples given by the authors as aids in the selection of an oil breaker for any particular duty are most valuable and will be of great service to the user and manufacturer. I am inclined to think however that the method as a whole is too complicated for practical use. It must be remembered that at the present time no generally accepted system whatever is in use. The step from this state of affairs to the very complete statement suggested by the authors is a very large one. A simpler proposal is, I consider, feasible, and while such would constitute a really very great advance over present day practise, it would be more likely to receive general support on account of its greater ease of application.

As an example of what I mean I would point out that the authors' method entails a statement of the time taken by the circuit breaker to open its contacts. This generally under practical conditions, is unknown. Moreover it is a very variable quantity, depending on the electrical and mechanical conditions of the controlling and operating mechanisms, and, in the case of electrically operated breakers, on the voltage of the operating battery. Practical considerations would therefore require an average assumption to be made in nearly all cases.

Seeing therefore that it will nearly always be necessary to make an assumption it seems to me unwise to complicate the issue in an attempt to secure a greater scientific exactitude than the original assumption will allow. I think that the following simple assumptions for example will probably be entirely sufficient.

$\left.\begin{array}{l}\text { Kilovolt amperes to be broken by } \\ \text { generator circuit breaker }\end{array}\right\}=0.6 \frac{(\text { Rated kv-a. } \times 100)}{\text { percentage generator }}$ reactance.

It will be seen that the factor 0.6 has been assumed to allow for the rapid fall of the short-circuit current from its high initial value before the circuit breaker has time to operate. Moreover the doubling effect has been neglected.

For oil circuit breakers at the ends of feeders it will be prob- 
ably quite sufficient to assume constant busbar voltage in the generating station and calculate the short circuit taking into account the impedance of the feeder. When dealing with feeders I do not think it right to neglect the resistance; this is especially so with underground cables.

I would also like to suggest that the examples given in the paper should be amplified by considering what happens when the oil circuit breaker interrupts a ring main, and also the effect of running synchronous motors.

Applying the simple formula given above to an alternator having 8 per cent total reactance we get $\mathrm{kv}-\mathrm{a}$. to be broken $=7.5$ times rated kv-a. This value on the authors curves (Fig. 2.) is obtained at 0.25 seconds from the time the short circuit begins. It is obvious that if the time taken by the circuit breaker to operate be shorter than 0.25 seconds, the factor 0.6 is too small. The question really resolves itself to determining what factor represents most closely the general results of experience.

I would like to suggest in conclusion that this simple statement of the usual case should be considered by the American Standardizing Authorities with the object of using it for the usual run of work and reserving the more detailed data of the authors for use on special occasions.

G. A. Burnham: Mr. Collins' question as to whether the authors had taken into consideration a single-phase short circuit on three-phase generating plants, was, I believe, fully covered by Mr. Willard's remarks. The authors feel, however, that for average application the curves give a sufficient factor of safety to take care of this condition.

With reference to Mr. Collins's statement wherein a highresistance fault may be so long developing into a so-called "dead short circuit" that the maximum current might occur at the instant when the switch contacts separated, is one of the factors which must be eliminated in the selection of breakers for average application, or else the breakers would have to be selected on the basis of instantaneous tripping, and this might mean for average conditions, a too conservative application.

Mr. Garrard has contributed an interesting discussion. It is possible that the words "dry conditions" in the absence of any remarks with reference to the dielectric tests for switching equipment for outdoor service might lead one to believe that the dry dielectric test was to be made without oil in the tank. This, however, is not the information which it was desired to convey. It is found necessary to differentiate in the dielectric tests for apparatus used for indoor service and for outdoor service. Apparatus for indoor service is to be tested under dry conditions, that is, the insulators and structure would be dry, but their tanks would be filled with oil to the proper level.

This difficulty will undoubtedly be cleared up in the near 
future, as there is before the Standards Committee at the present time recommendations for the dilectric test of apparatus to be used indoors and also apparatus for use out of doors.

I do not entirely agree with Mr. Garrard that the kv-a. rating or rupturing capacity of a given breaker is independent of the voltage. There seems to be quite a difference of opinion in America in reference to this point. It is undoubtedly true within reasonable limits, but circuit breakers designed for a given $\mathrm{kv}$-a. interrupting capacity for a given voltage probably would not interrupt the energy in a circuit of equal kv-a. capacity on a very low voltage. It would be necessary, therefore, to give different $\mathrm{kv}$-a. ratings for the same circuit breaker when used on voltages differing widely from the maximum rated voltage.

If all generators had the same reactance and time-current decrement curves, and all transformers had the same reactance, irrespective of their kv-a. capacity, and that it would be assumed that the $\mathrm{kv}-\mathrm{a}$. interrupting capacity of a circuit breaker was dependent only on the product of the current and voltage at the instant of the parting of the circuit breaker contacts, the $\mathrm{kv}-\mathrm{a}$. basis of interrupting capacity would undoubtedly offer advantages. These assumptions have evidently been the basis of Mr. Garrard's recommendations for determining the $\mathrm{kv}-\mathrm{a}$. to be interrupted by generator circuit breakers. It would seem, however, that circuit breakers when called upon to trip within a second to a second and a half after the occurrence of a short circuit would not be applied as conservatively in many cases as would be required, and, on the other hand, in many instances would be very much larger than required.

I fully agree with Mr. Garrard that resistance should not be neglected when dealing with feeders alone; as it has a very modifying effect upon the short-circuit current, particularly as he mentions on underground systems. However, when considering feeder circuits in conjunction with reactors, transformers and the reactance of generators, the effect of resistance as to the value of the short-circuit current is usually relatively small.

Mr. Jones' and Mr. Torchio's remarks concerning standardization are of great interest to the manufacturer. Certainly, if we can arrive at some form of standardization, if only applying to structure, mounting, etc., it will relieve the manufacturers of a great deal of special engineering and hasten the production of standard apparatus.

Standardization is a most important factor. If engineers, in laying out their plans, gave this matter more serious consideration, I can assure you it would be of great economic value, particularly in the moderate sized installation.

In reference to using factors to modify values representing the interrupting capacity of oil circuit breakers where conditions cause widely different re-established voltages, I do not believe it is possible with the data at hand. 
I might answer Mr. Hunt and Mr. Pollard on the question of knowing more about the various factors mentioned and the relative effect which they have on the circuit breaker interrupting capacity. At the present time there is no suitable apparatus that would allow one to determine with any degree of accuracy the relative effects of the various factors mentioned. It is a question of a long field experience, or, in other words, careful observation of the particular piece of apparatus under widely varying conditions. The circuit breaker manufacturer would welcome any suggestions that would be of assistance in giving more information pertaining to the action of oil switching equipment. Mr. Pollard and Mr. Hunt also brought up the question that even after the paper had been presented and even after these curves were published by the manufacturers, it would then be practically impossible to make application of them. I think with the general publications as they are today that it is true, to a certain extent, but in the newer publications which all manufacturers are preparing, proper information will be available. There will undoubtedly be listed the minimum tripping time of each type and form of circuit breaker, also the minimum tripping time of various forms of relays that are associated with circuit breakers in order that the total lapse of time may be determined. It will then only be necessary for the customer to determine his relay settings to arrive at the maximum time from the instant of short circuit to the parting of the contacts, and, knowing his reactance, pick out the current value from the transient current curves.

I believe that this will take care of a great deal of the difficulty that we are encountering at present.

Mr. Dewey's and Mr. Willard's remarks cover the question of average systems. It cannot be described in a few words, but I believe these curves, with the exception of the few conditions pointed out, will apply in probably 75 per cent of the applications.

I want to emphasize Mr. Lincoln's statement in reference to cooperation between the user and the manufacturer. The manufacturer tries to get all possible information pertaining to the system to assist the customer in making proper application. A closer cooperation will result in a better understanding of the situation, not only from the standpoint of the customer with reference to the manufacturer, but of the manufacturer in reference to the customer's viewpoint.

The real object of this paper was to state as clearly as we could terms which could be used so that when each of us got through with a problem and assumed the same conditions, we would arrive at the same conclusion. As Mr. Hewlett pointed out, we desire to establish a bench mark to be used by all, and this will allow a more consistent conclusion in the analysis of the various circuit breaker problems. 